International Journal of Innovative Engineering Applications

\title{
EFFECT OF BISMUTH ADDITION ON THE CORROSION DYNAMICS OF Sn-3Ag-0.5Cu SOLDER ALLOY IN HYDROCHLORIC ACID SOLUTION
}

\author{
Ahmet Mustafa Erer" ${ }^{* 1}$ iD \\ ${ }^{1}$ Karabük University, Science Faculty, Physics Department, 78000 Karabük-Turkey
}

\section{Abstract}

Original scientific paper

This study aims to investigate the effects of bismuth addition on the corrosion behaviour of $\mathrm{Sn}-3.0 \mathrm{Ag}-0.5 \mathrm{Cu}$ (SAC 305$)$ solder alloy in $1 \mathrm{M} \mathrm{HCl}$ acid solution under potentiodynamic polarization. After electrochemical tests, scanning electron microscopy (SEM) and energy dispersive X-ray spectroscopy (EDX) were used to examine and characterize the properties of the samples. Polarization studies indicate that the addition of $0.5,1$, and $2 \mathrm{wt} . \% \mathrm{Bi}$ in the SAC305 solder alloy does not significantly change the corrosion potentials. Instead of a true passivation region, a pseudo-passivation region is observed in which currents are nearly constant (though high). This pseudo-passive region does not include a reactivation point within the scanning interval. On the other hand, the corrosion rates follow a pattern in which 1 wt.\% bismuth replacement of silver causes a decrement in corrosion rate. However, the corrosion rate increases with the further replacement of silver with bismuth. Microstructure analysis reveals the existence of gaps and porosities which introduce limits on the formation and stability of protective passive corrosion products.

Keywords: Bi-addition, corrosion, microstructure, Pb-free solder alloys, potentiodynamic polarization, HCl acid solution.

\section{Introduction}

Solder alloys are used to provide mechanical integration and electrical connection of electrical circuit elements in the electronics industry [1]. Lead $(\mathrm{Pb})$ containing solder alloys have been widely used commercially for many years in electronics applications [2]. Sn-Pb soldering alloys have been accepted as the most reliable product as interconnection material in electrical and electronic devices. The low melting temperature, eutectic structure, affordable cost, high wetting ability, and good mechanical properties make this alloy an excellent interconnection material [3].

However, due to increasing health and environmental concerns regarding the element of $\mathrm{Pb}$, many countries and organizations around the world have legislated laws to limit the use of $\mathrm{Pb}$ in electronic applications [4]. In electronic devices and other products containing solder, the Restriction of Hazardous Substances (RoHS) directive of the European Union limits the use of heavy metals and hazardous substances [5].

For this reason, the search for lead-free solder alloys, which can be an alternative to $\mathrm{Pb}$-containing solder alloys, has become an important research topic in the electronics industry. In this context, various Sn-based unleaded solder alloys such as $\mathrm{Sn}-\mathrm{Ag}, \mathrm{Sn}-\mathrm{Cu}, \mathrm{Sn}-\mathrm{Zn}, \mathrm{Sn}-\mathrm{Bi}, \mathrm{Sn}-\mathrm{In}$, and $\mathrm{Sn}-\mathrm{Ag}-\mathrm{Cu}$ (SAC) have been developed [4]. SAC alloys are candidates that can be an alternative to $\mathrm{Sn}-\mathrm{Pb}$ solder alloys due to their relatively lower cost, low melting temperature, and superior mechanical properties among the types of Pb-free solder alloys [6]. The reliability of high-performance connection materials is very important for the long-lasting use of electronic devices. Compared to other ternary $\mathrm{Pb}$-free soldering alloys, SAC305 alloy has started widespread use as an electrical conduction material in the microelectronics industry and in the connection of devices, due to its lower melting temperature, high wetting ability, and higher mechanical durability $[7,8]$.

In recent years, there have been studies on the corrosion behavior of $\mathrm{Pb}$-free solder alloys, especially SAC305 alloys [9]. Such as Wang et al. have investigated the corrosion behavior of SAC305 solder alloy using 5\% sodium chloride $(\mathrm{NaCl})$ solution by weight. They noted that the SAC305 solder joint acts as an anode by itself and has less corrosion potential than that of $\mathrm{Cu}$, which acts as cathode [10]. Nurwahida et al. examined the effect of $1 \mathrm{M}$ hydrochloric acid $(\mathrm{HCl})$ solution on the corrosion performance of SAC305 and compared its corrosion properties with $3.5 \% \mathrm{NaCl}$ solution by weight. Meanwhile, they revealed that the dispersion of small and homogeneous $\mathrm{Ag}_{3} \mathrm{Sn}$ intermetallic particles in the rich $\mathrm{Sn}$ matrix plays an important role in corrosion resistance, as it can determine the corrosion performance of SAC305 [11]. So far, $\mathrm{NaCl}[12,13]$ solution has been used in various studies on the corrosion properties of SAC305. However, such studies are limited to low $\mathrm{pH} \mathrm{HCl}$ environment, which is known as highly aggressive environment for metallic alloys. 
The purpose of this work is to determine the effect of $\mathrm{Bi}$ on the corrosion dynamics of $\mathrm{Sn}-(3-\mathrm{x}) \mathrm{Ag}-0.5 \mathrm{Cu}-\mathrm{xBi}$ (where $\mathrm{x}=0,0.5,1$, and 2) in $1 \mathrm{M} \mathrm{HCl}$ acid solution. Corrosion tests have been performed in $\mathrm{HCl}$ solution by potentiodynamic polarization. Scanning electron microscope (SEM) coupled with energy dispersive X-ray analysis (EDX) were used to determine compositions of the corrosion products.

\section{Experimental}

In the present work, we study the corrosion properties of the new low-Ag-content quaternary $\mathrm{Pb}$-free solder alloys produced by adding $\mathrm{xBi}(\mathrm{x}=0.5,1$ and $2 \%)$ to the SAC305 alloy in our previous study [14]. The chemical compositions of the samples are given in Table 1.

Table 1. The chemical composition of alloys tested ( $\mathrm{wt} \%$ ).

\begin{tabular}{lccccccc}
\hline Alloys & Sn & Ag & Cu & Bi & Mg & Al & Fe \\
\hline SAC-0.5Bi & 96.2206 & 2.6841 & 0.5029 & 0.4554 & 0.0574 & 0.0504 & 0.0212 \\
\hline SAC-1Bi & 96.4083 & 2.0100 & 0.4967 & 0.9912 & 0.0283 & 0.0491 & 0.0164 \\
\hline SAC-2Bi & 96.4655 & 1.0252 & 0.4787 & 1.9832 & 0.0000 & 0.0249 & 0.0225 \\
\hline SAC305 & 96.5000 & 2.9800 & 0.4900 & 0.0000 & 0.0120 & 0.0000 & 0.0180 \\
\hline
\end{tabular}

In order to determine individual phases (crystal structures) and corresponding diffraction planes formed in the microstructure of SAC305 and SAC-xBi $(0.5,1$ and 2 wt.\%) Pb-free alloys, we applied an X-ray diffraction (XRD) analysis using a "RIGAKU - ULTIMA IV" machine. Microstructural analysis was examined before and after corrosion measurements by using "CARL ZEISS ULTRA PLUS GEMINI FESEM" and "Q150R ROTARY-PUMPED SPUTTER COATER / CARBON COATER" model SEM device [15].

Specimens of working electrodes are polished with $\mathrm{SiC}$ papers of mesh sizes starting with 400 and ending with 1200 . As a last step of polishing, we used a solution of $\mathrm{Al}_{2} \mathrm{O}_{3}$ microparticles on a smooth napless cloth. Polished specimens were cleaned with alcohol and dried immediately. Before polarizations, an open circuit monitoring was held for 10 minutes to ensure potentiostatic stabilization of working electrode surfaces. We used $\mathrm{Ag} / \mathrm{AgCl}$ reference electrode with a pair of graphite rods as the counter electrode with specimens as the working electrodes of the usual three-electrode setup. A $1 \mathrm{M} \mathrm{HCl}$ acid solution was chosen as a highly aggressive environment for our specimens to determine the lowest limits of corrosion resistance. We scanned potentials between $-1.0 \mathrm{~V}$ vs. $\mathrm{Ag} / \mathrm{AgCl}$ and $+1.0 \mathrm{~V}$ vs. $\mathrm{Ag} / \mathrm{AgCl}$ to ensure to locate possible passivation and de-passivation regions. The scanning rate was $1 \mathrm{mV} / \mathrm{s}$.

\section{Results and discussion}

\subsection{Solder characterization}

Figure 1 presents the microstructures of SAC305 and SAC-xBi (0.5, 1 and 2 wt.\%) alloys. The hollow structures seen in the SEM analysis show the $\beta$-Sn matrix which are $\mathrm{Sn}$ rich areas. $\mathrm{Cu}_{6} \mathrm{Sn}_{5}$ is the large particles of $\mathrm{Sn}-\mathrm{Cu}$ intermetallics, while the structures consisting of small particles are $\mathrm{Ag}_{3} \mathrm{Sn}$ intermetallic particles. Meanwhile it is also seen that $\mathrm{Ag}_{3} \mathrm{Sn}$ and $\mathrm{Cu}_{6} \mathrm{Sn}_{5}$ phases dispersed in $\beta$ Sn matrix contain full eutectic structure $[16,17]$. As can be seen from the tin-bismuth equilibrium diagram in the literature $[18,19]$, it forms up to $2 \% \mathrm{Bi}$ solid solution at room temperature. Therefore, the secondary phases associated with Bi do not appear in Fig. 1.

Fig. 2 shows the XRD results of the solder alloy samples under consideration. In accordance with the microstructure results mentioned above, the peaks are associated with the Sn-rich phases for all specimens, with the presence of $\mathrm{Ag}_{3} \mathrm{Sn}$ and $\mathrm{Cu}_{6} \mathrm{Sn}_{5}$ intermetallics for the $\mathrm{Sn}-\mathrm{Ag}$ and $\mathrm{Sn}-\mathrm{Cu}$ alloys, respectively [20].
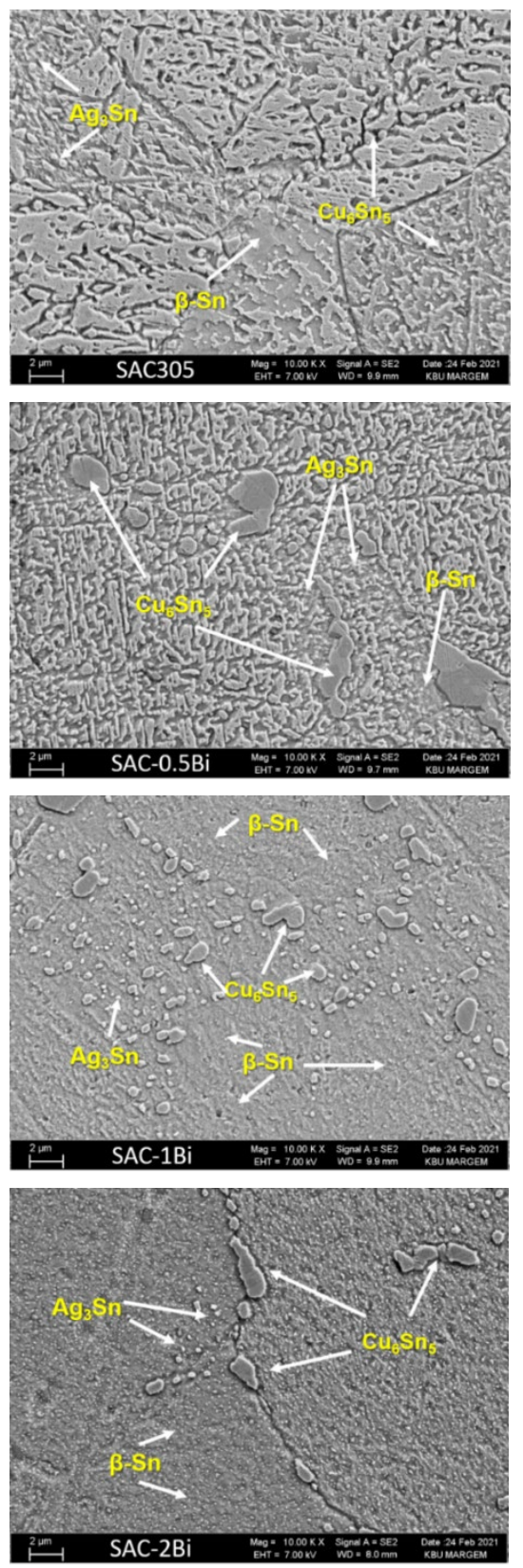

Figure 1. SEM images for the as-prepared SAC305 and SAC-xBi $(0.5,1$ and 2 wt. $\%)$ 

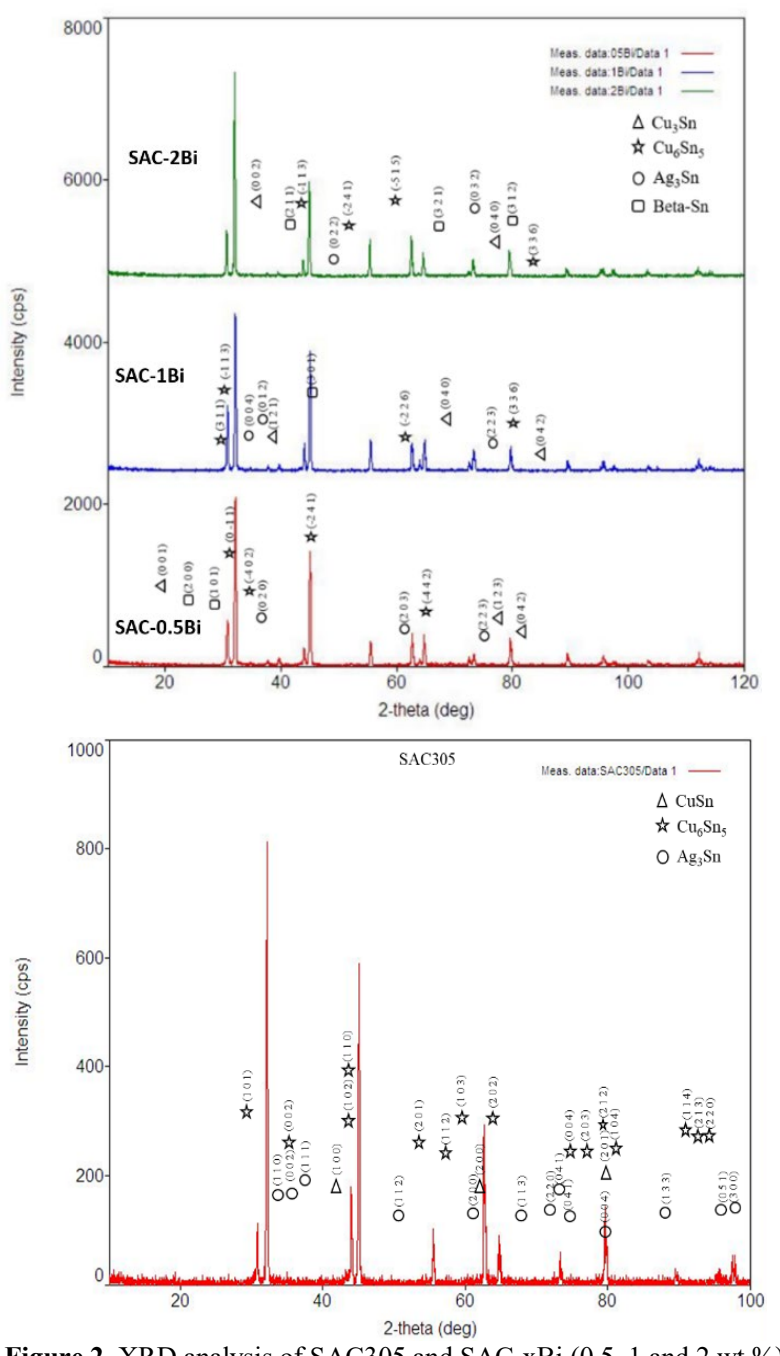

Figure 2. XRD analysis of SAC305 and SAC-xBi (0.5, 1 and 2 wt.\%).

\subsection{Potentiodynamic Polarization Analysis}

Plots of potentiodynamic polarization scanning are given in Fig. 3. The absence of passivation regions is clear. In a passivation region, the current density should change its course at some specific potential of anodic polarization and accept very low values compared to values observed just before entering the region. Instead, SAC305 and SAC-xBi $(0.5,1$ and 2 wt.\%) have only a pseudo-passivation region in which current densities are constant and do not react to changes in scanning potentials from about $+0.1 \mathrm{~V}$ to the end of the scanning region $(+1.0$ V). All bismuth-containing sub-alloys enter this pseudopassivation region slightly later (with $0.1 \mathrm{~V}$ difference) than SAC305. Note that the current density in pseudopassivation regions is much higher than one can have with $\mathrm{NaCl}$ solution [21]. This should be expected because of the extreme acidity of the $1 \mathrm{M} \mathrm{HCl}$ environment. Another interesting point is that the lack of a reactivation point at which the pseudo-passivation region ends. As one can easily see from Fig. 3, even at the end of the scanning region $(+1.0 \mathrm{~V})$ pseudo-passivation region holds. This is different from the observed behavior reported by other studies which mainly used $\mathrm{NaCl}$-based solutions [22,23]. The quantitative results of potentiodynamic polarization measurements are given in Table 2. We observed similar corrosion potentials for all the alloys within this study.
This is expected as the ratios of bismuth within these alloys are not high enough to trigger a significant change. Using Tafel extrapolations, we obtain corrosion current densities with corresponding corrosion rates of each alloy. It seems that overall corrosion rates follow a pattern in which \%1.0 bismuth replacement of silver causes a dropin corrosion rate. With the further replacement of silver with bismuth, however, the corrosion rate increases.

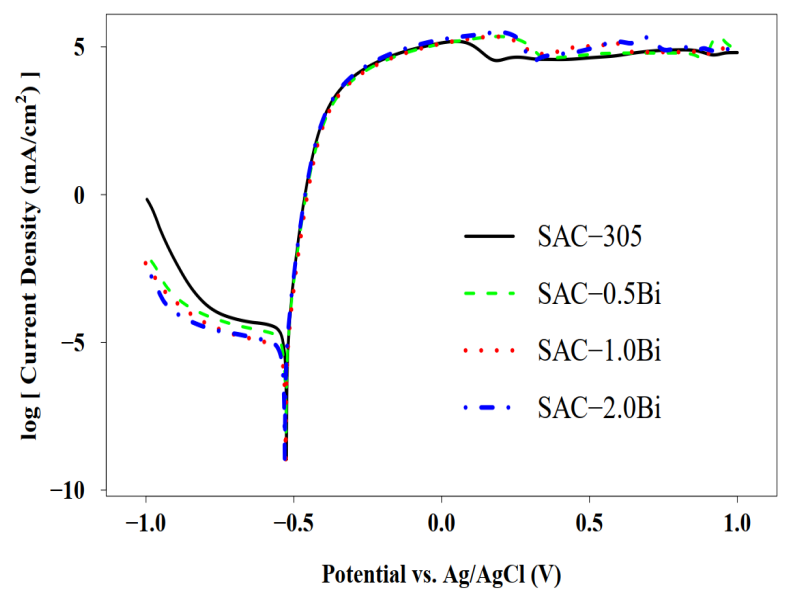

Figure 3. Potentiodynamic polarization curves of SAC 305 and $\mathrm{SAC}-\mathrm{xBi}$ $(0.5,1$ and 2 wt. $\%)$.

Table 2. Corrosion parameters of SAC 305 and SAC-xBi $(0.5,1$ and 2 wt.\%) in $1 \mathrm{M} \mathrm{HCl}$ acid solution.

\begin{tabular}{|c|c|c|c|}
\hline Specimen & $\mathrm{i}_{\text {corr }}\left(\mu \mathrm{A} / \mathrm{cm}^{2}\right)$ & $\mathrm{CR}(\mathrm{mm} /$ year $)$ & $\mathrm{E}_{\text {corr }}(\mathrm{V})$ \\
\hline $\mathrm{SAC}-0.5 \mathrm{Bi}$ & 17.286 & 0.466 & -0.527 \\
\hline $\mathrm{SAC}-1 \mathrm{Bi}$ & 11.063 & 0.298 & -0.528 \\
\hline $\mathrm{SAC}-2 \mathrm{Bi}$ & 14.056 & 0.379 & -0.530 \\
\hline $\mathrm{SAC} 305$ & 18.095 & 0.488 & -0.525 \\
\hline
\end{tabular}

The low Corrosion Current Density ( $\left.i_{\text {corr }}\right)$ value means that the corrosion rate is low, and the higher the current density the higher the corrosion rate. Up to $1 \% \mathrm{Bi}$ addition to the SAC305 solder alloy, the $i_{\text {corr }}$ values decrease. It tends to increase again after this value. However, the $i_{\text {corr }}$ values are still lower than the SAC305 solder alloy. When the corrosion rate is examined, it can be said that the SAC$1 \mathrm{Bi}$ alloy with the lowest rate is more resistant to corrosion than the SAC305 alloy.

\subsection{Post-corrosion characterizations}

In Figure 4, the SEM views of the analysed solder alloys are given after potentiodynamic testing. With the increase of Bi addition to SAC305 solder alloy, it is seen that the oxide film formed as a corrosion product gradually becomes coarse and it finally becomes spherical at $2 \% \mathrm{Bi}$ addition. As can be seen from EDX analysis of corrosion products as given in Table 3 , it is observed that corrosion products have larger $\mathrm{Ag}$ content by weight up to $1 \% \mathrm{Bi}$ addition. In case of adding more $\mathrm{Bi}$ (i.e. $2 \% \mathrm{Bi}$ addition), the regions containing large spherical $\mathrm{Cu}$ increase.

The occurrence of copper-rich corrosion products yields reduced corrosion resistance. This is due to the formation of the $\mathrm{Cu}_{6} \mathrm{Sn}_{5}$ phase (Fig. 1), which is distributed along the grain boundaries in microstructure studies. 

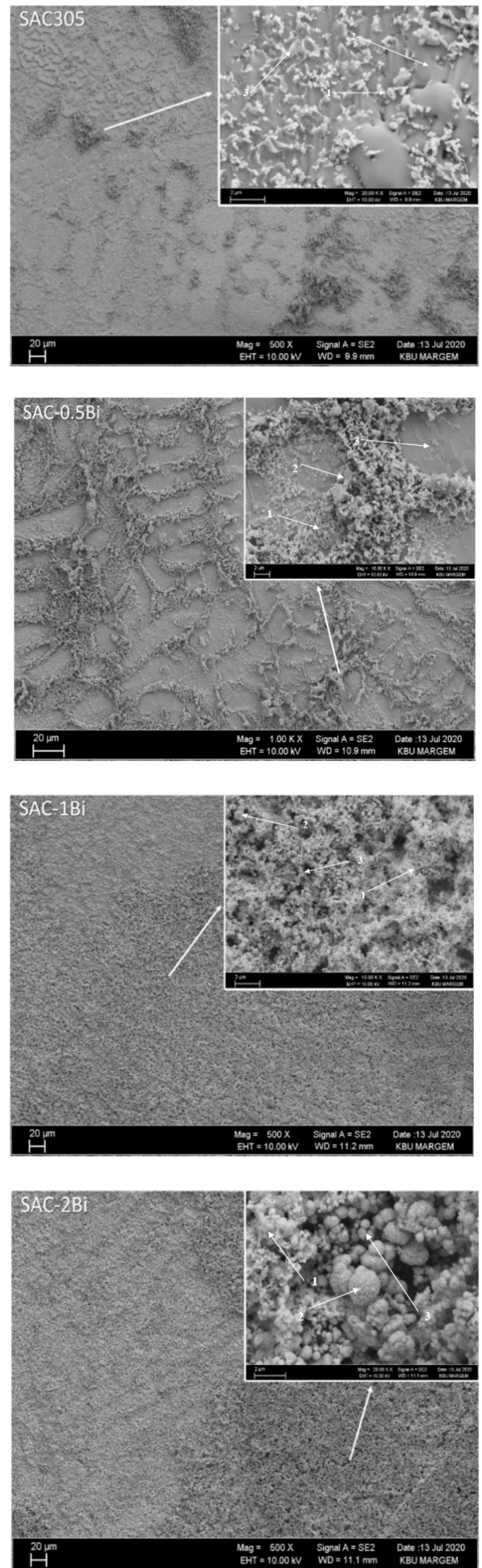

Figure 4. SEM analysis of SAC305 and SAC-xBi $(0.5,1$ and 2 wt.\%) solder alloys after immersion in $1 \mathrm{M} \mathrm{HCl}$ solution.
Table 3. EDX analysis of (a) SAC305, (b) SAC-0.5Bi, (c) SAC-1Bi and (d) SAC-2Bi solder alloys after immersion in $1 \mathrm{M} \mathrm{HCl}$ solution.

\begin{tabular}{|l|l|l|l|}
\hline Mass Percent (\%) & \multicolumn{1}{c|}{ (a) } \\
\hline Spectrum & Cu & Ag & Sn \\
\hline $\mathbf{1}$ & 9.3375 & 17.4275 & 73.235 \\
\hline $\mathbf{2}$ & 5.2767 & 6.2467 & 88.4767 \\
\hline $\mathbf{3}$ & 8.57 & 7.38 & 84.055 \\
\hline Mean value & 7.728 & 10.3514 & 81,923 \\
\hline
\end{tabular}

\begin{tabular}{|l|l|l|l|l|}
\hline Mass Percent (\%) & \multicolumn{2}{c|}{ (b) } \\
\hline Spectrum & $\mathbf{C u}$ & $\mathbf{A g}$ & Sn & $\mathbf{B i}$ \\
\hline $\mathbf{1}$ & 0.61 & 63.26 & 25.45 & 10.68 \\
\hline $\mathbf{2}$ & 35.455 & 21.33 & 38.38 & 4.835 \\
\hline $\mathbf{3}$ & 2.98 & 4.16 & 92.17 & 0.69 \\
\hline Mean value & 13.015 & 29.583 & 52 & 5.403 \\
\hline
\end{tabular}

\begin{tabular}{|l|l|l|l|l|}
\hline \multicolumn{4}{|l|}{ Mass Percent (\%) } \\
\hline Spectrum & Cu & Ag & Sn & Bi \\
\hline $\mathbf{1}$ & 1.335 & 15.355 & 9.37 & 73.95 \\
\hline $\mathbf{2}$ & 2.3725 & 56.75 & 13.4875 & 27.3925 \\
\hline $\mathbf{3}$ & 0.74 & 34.43 & 10.16 & 54.67 \\
\hline Mean value & 1.4825 & 35.512 & 11.0058 & 52.0042 \\
\hline
\end{tabular}

\begin{tabular}{|l|l|l|l|l|}
\hline Mass Percent (\%) & \multicolumn{1}{r|}{ (d) } \\
\hline Spectrum & $\mathbf{C u}$ & $\mathbf{A g}$ & Sn & $\mathbf{B i}$ \\
\hline $\mathbf{1}$ & 6.39 & 3,83 & 17.565 & 72.215 \\
\hline $\mathbf{2}$ & 24.30 & 2.30 & 23.36 & 50.04 \\
\hline $\mathbf{3}$ & 6.8625 & 37.945 & 21.29 & 33.91 \\
\hline Mean value & 12.5175 & 14.6917 & 20.7383 & 52.055 \\
\hline
\end{tabular}

\section{Conclusion}

In this work, the corrosion behaviours of SAC305 and $\mathrm{SAC}-\mathrm{xBi}(0.5,1$ and $2 \mathrm{wt} \%)$ alloys were investigated in $1 \mathrm{M} \mathrm{HCl}$ acidic solution ( $\mathrm{pH}=0)$. It was found that similar $\mathrm{E}_{\text {corr }}$ and $\mathrm{i}_{\text {corr }}$ for all alloys. This is expected, since the ratios of bismuth within these alloys are not high enough to trigger a significant change. It seems that overall corrosion rates follow a pattern in which \%1.0 bismuth replacement of silver causes a drop-in corrosion rate. With the further replacement of silver with bismuth, however, the corrosion rate increases.

\section{Acknowledgements}

We undertake that in the article we submitted for publication, no study, requiring ethics committee approval, was conducted.

\section{References}

[1] Li, S., Wang, X., Liu, Z., Jiu, Y., Zhang, S., Geng, J., ... \& Long, W. (2020). Corrosion behavior of Sn-based lead-free solder alloys: a review. Journal of Materials Science: Materials in Electronics, 31, 9076-9090.

[2] Zaini, N. B. M., \& Nazeri, M. F. B. M. (2016, July). Potentiodynamic polarization effect on phase and microstructure of SAC305 solder in hydrochloric acid solution. In AIP Conference Proceedings (Vol. 1756, No. 1, p. 030007). AIP Publishing LLC.

[3] Jaffery, H. A., Sabri, M. F. M., Said, S. M., Hasan, S. W., Sajid, I. H., Nordin, N. I. M., ... \& Moorthy, C. V. (2019). Electrochemical corrosion behavior of $\mathrm{Sn}-0.7 \mathrm{Cu}$ solder alloy with the addition of bismuth and iron. Journal of Alloys and Compounds, 810, 151925. 
[4] Sun, L., \& Zhang, L. (2015). Properties and microstructures of $\mathrm{Sn}-\mathrm{Ag}-\mathrm{Cu}-\mathrm{X}$ lead-free solder joints in electronic packaging. Advances in Materials Science and Engineering, 2015.

[5] Tunthawiroon, P., \& Kanlayasiri, K. (2019). Effects of Ag contents in $\mathrm{Sn}-\mathrm{xAg}$ lead-free solders on microstructure, corrosion behavior and interfacial reaction with $\mathrm{Cu}$ substrate. Transactions of Nonferrous Metals Society of China, 29(8), 1696-1704.

[6] Gharaibeh, A., Felhősi, I., Keresztes, Z., Harsányi, G., Illés, B., \& Medgyes, B. (2020). Electrochemical Corrosion of SAC Alloys: A Review. Metals, 10(10), 1276.

[7] Sonawane, P. D., Raja, V. B., \& Gupta, M. (2021). Mechanical properties and corrosion analysis of lead-free $\mathrm{Sn}-0.7 \mathrm{Cu}$ solder CSI joints on $\mathrm{Cu}$ substrate. Materials Today: Proceedings, 46, 1101-1105.

[8] Rosalbino, F., Angelini, E., Zanicchi, G., Carlini, R., \& Marazza, R. (2009). Electrochemical corrosion study of Sn$3 \mathrm{Ag}-3 \mathrm{Cu}$ solder alloy in $\mathrm{NaCl}$ solution. Electrochimica Acta, 54(28), 7231-7235.

[9] Mohamed, M. N., Aziz, N. A., Mohamad, A. A., \& Nazeri, M. F. M. (2015). Polarization study of Sn-9Zn and Sn-37Pb solders in hydrochloric acid solution. Int. J. Electroactive Mater, 3, 28-32.

[10] Li, S., Wang, X., Liu, Z., Jiu, Y., Zhang, S., Geng, J., ... \& Long, W. (2020). Corrosion behavior of Sn-based lead-free solder alloys: a review. Journal of Materials Science: Materials in Electronics, 31, 9076-9090.

[11] Nurwahida, M. Z., Mukridz, M. M., Ahmad, A. M., \& Muhammad, F. M. N. (2018, March). Corrosion properties of SAC305 solder in different solution of $\mathrm{HCl}$ and $\mathrm{NaCl}$. In IOP Conference Series: Materials Science and Engineering (Vol. 318, No. 1, p. 012004). IOP Publishing.

[12] Fayeka, M., Haseeb, A. S. M. A., \& Fazal, M. A. (2017). Electrochemical corrosion behaviour of $\mathrm{Pb}$-free SAC 105 and SAC 305 solder alloys: a comparative study. Sains Malays, 46(2).

[13] See, C. W., Yahaya, M. Z., Haliman, H., \& Mohamad, A. A. (2016). Corrosion behavior of corroded Sn-3.0 Ag- 0.5 $\mathrm{Cu}$ solder alloy. Procedia Chemistry, 19, 847-854.
[14] Erer, A. M., \& Oguz, S. (2019). Wetting characteristic of $\mathrm{Sn}-(3-\mathrm{x}) \mathrm{Ag}-0.5 \mathrm{Cu}-\mathrm{xBi}$ quaternary solder alloy systems. Soldering \& Surface Mount Technology.

[15] Oguz, S. (2018). Sn-(3-x)Ag-0.5Cu-xBi dörtlü kurşunsuz lehim alaşımlarının ıslatma özelliklerinin $\mathrm{Cu}$ altlık üzerinde incelenmesi,, Institute of Science of Karabük University, Karabük.

[16] El-Taher, A. M., \& Razzk, A. F. (2020). Controlling Ag 3 Sn Plate Formation and Its Effect on the Creep Resistance of $\mathrm{Sn}-3.0 \mathrm{Ag}-0.7 \mathrm{Cu}$ Lead-Free Solder by Adding Minor Alloying Elements $\mathrm{Fe}, \mathrm{Co}, \mathrm{Te}$ and Bi. Metals and Materials International, 1-12.

[17] Subri, N. W. B., Sarraf, M., Nasiri-Tabrizi, B., Ali, B., Mohd Sabri, M. F., Basirun, W. J., \& Sukiman, N. L. (2020). Corrosion insight of iron and bismuth added Sn$1 \mathrm{Ag}-0.5 \mathrm{Cu}$ lead-free solder alloy. Corrosion Engineering, Science and Technology, 55(1), 35-47.

[18] Wang, F., Huang, Y., Zhang, Z., \& Yan, C. (2017). Interfacial reaction and mechanical properties of $\mathrm{Sn}-\mathrm{Bi}$ solder joints. Materials, 10(8), 920

[19] Braga, M. H., Vizdal, J., Kroupa, A., Ferreira, J., Soares, D., $\&$ Malheiros, L. F. (2007). The experimental study of the $\mathrm{Bi}-\mathrm{Sn}, \mathrm{Bi}-\mathrm{Zn}$ and $\mathrm{Bi}-\mathrm{Sn}-\mathrm{Zn}$ systems. Calphad, 31(4), 468478.

[20] Osorio, W. R., Peixoto, L. C., Garcia, L. R., Garcia, A., \& Spinelli, J. E. (2012). The effects of microstructure and Ag3Sn and Cu6Sn5 intermetallics on the electrochemical behavior of $\mathrm{Sn}-\mathrm{Ag}$ and $\mathrm{Sn}-\mathrm{Cu}$ solder alloys. Int. J. Electrochem. Sci, 7(7), 6436-6452.

[21] Chen, G., Wang, X. H., Yang, J., Xu, W. L., \& Lin, Q. (2020). Effect of micromorphology on corrosion and mechanical properties of SAC305 lead-free solders. Microelectronics Reliability, 108, 113634.

[22] Kaushik, R. K., Batra, U., \& Sharma, J. D. (2018). Aging induced structural and electrochemical corrosion behaviour of Sn-1.0 Ag-0.5 Cu and Sn-3.8 Ag-0.7 Cu solder alloys. Journal of Alloys and Compounds, 745, 446-454.

[23] Tsao, L. C., \& Chen, C. W. (2012). Corrosion characterization of $\mathrm{Cu}-\mathrm{Sn}$ intermetallics in 3.5 wt. $\% \mathrm{NaCl}$ solution. Corrosion science, 63, 393-398. 